Revista de Comunicación y Salud, 2019, Vol. 9, n² 2, pp. 55-70

Editado por Cátedra de Comunicación y Salud

ISSN: 2173-1675

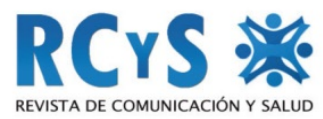

Enviado 19/11/2019

Aprobado 20/12/2019

\title{
NUEVAS HERRAMIENTAS DE COMUNICACIÓN DIGITALES ENTRE PROFESIONALES DE LA SALUD Y PACIENTES. A PROPÓSITO DEL PROYECTO DEJAL@BOT
}

\section{New digital communication tolos between health professionals and patients. About the dejal Dejal@Bot project}

\author{
José Francisco Ávila-Tomás. ${ }^{1}$ Centro de Salud Sta. Isabel. España. \\ Eduardo Olano-Espinosa. Universidad Rey Juan Carlos. Centro de Salud Los \\ Castillos. España. \\ César Minué-Lorenzo. Centro de Salud Perales del Río. España. \\ Francisco Javier Martínez-Suberbiola, Centro de Salud Guayaba. España. \\ Blanca Matilla-Pardo, Centro de Salud Panaderas. España. \\ Encarnación Serrano-Serrano, Centro de Salud Los Fresnos. España. \\ Grupo Dejal@Bot
}

\section{Resumen}

La comunicación es una habilidad humana que permite relacionarnos; construir nuestra identidad (individual, grupal y colectiva); compartir normas, hábitos y conductas e ir evolucionando personal y socialmente a partir de la creación, desarrollo y adquisición de nuevos conocimientos y habilidades. La comunicación en salud es especial por la asimetría entre el sanitario y el paciente. Su objetivo es curar, prevenir enfermedades o potenciar aptitudes y actitudes saludables. Su base (anamnesis) es muy concreta. EI paciente expone su motivo de consulta y el sanitario obtiene datos que orientan la exploración para obtener un diagnóstico y tratamiento. La aparición de herramientas digitales para comunicarnos está modificando esta relación debido a su comodidad e inmediatez, ambos aspectos muy apreciados por la población, y los sanitarios no podemos permanecer ajenos. Las innovaciones tecnológicas se desarrollan a mayor velocidad que los ajustes en materia de ética y legislación ¿Qué ocurre cuando uno de los sujetos del acto de la comunicación no es humano? Se define chatbot como un robot conversacional que integra un sistema experto o inteligencia artificial que permite una conversación con un humano. El desarrollo de chatbots en salud todavía es escaso, pero va a ser una herramienta cada vez más habitual en los próximos años por su gran eficiencia, planteando retos tecnológicos, sociales, éticos, comunicativos y

\footnotetext{
${ }^{1}$ Autor para correspondencia: José Francisco Ávila-Tomás jose.avila@salud.madrid.org
} 
Nuevas herramientas de comunicación digitales entre profesionales de la salud y pacientes. A propósito del proyecto Dejal@Bot

sanitarios. El proyecto Dejal@Bot es el primer ensayo clínico independiente y realizado en Atención Primaria de Salud para ayudar a los pacientes a dejar de fumar asistidos por un chatbot. Ello ha generado problemas de comunicación humano-máquina reflejados en éste artículo.

Palabras clave: comunicación, salud, chatbot, inteligencia artificial, sistemas expertos, big data.

\section{Abstract}

Communication is a human ability that allows us to relate; build our identity (individual, groupal and collective); share norms, habits and behaviors and evolve personally and socially from the creation, development and acquisition of new knowledge and skills. Health communication is special because of the asymmetry between the professional and the patient. Its objective is to cure, prevent diseases or strengthen healthy attitudes and aptitudes. Its base (anamnesis) is very concrete. The patient sets out his reason for consultation and the healthcare provider obtains data that guides the exploration to obtain a diagnosis and treatment. The emergence of digital tools to communicate is changing this relationship for their comfort and immediacy, aspects highly appreciated by the population, and the healthcare providers cannot remain outside. Technological innovations develop faster than adjustments in ethics and legislation. What will happen when one of the subjects of the communication act is not human? A Chatbot is defined as a conversational robot that integrates an expert system or artificial intelligence that allows a conversation with a human. The development of health chatbots is still scarce, but it will be a more and more usual tool in the coming years due to its great efficiency, posing technological, social, ethical, communicative and health challenges. The DejaloBot project is the first independent clinical trial conducted in Primary Health Care to help patients quit smoking assisted by a chatbot. This has generated human-machine communication problems displayed in this article.

Keywords: communication, health, chatbot, artificial intelligence, expert systems, big data.

\section{Cómo citar el artículo}

Ávila-Tomás, J. F., et al. (2019). Nuevas herramientas de comunicación digitales entre profesionales de la salud y pacientes. A propósito del proyecto Dejal@Bot. Revista de Comunicación y Salud, 9(2), 55-70.

doi: http://doi.org/10.35669/revistadecomunicacionysalud.2019.9(2).55-70

\section{EL APRENDIZAJE DE LAS MÁQUINAS. COMUNICACIÓN ENTRE EL HOMBRE Y LA MÁQUINA}

Las máquinas pueden aprender de forma parecida al ser humano mediante el método de la exposición repetida a situaciones con soluciones similares. La experiencia nos lleva a tomar decisiones que previamente han sido útiles para la resolución de

Revista de Comunicación y Salud, 2019, Vol. 9, n² 2, pp. 55-70 
Nuevas herramientas de comunicación digitales entre profesionales de la salud y pacientes. A propósito del proyecto Dejal@Bot

problemas parecidos en nuestro pasado, generando soluciones abstractas a partir de elementos cotidianos concretos. Es el condicionamiento operativo, uno de los principios por los que se rige nuestra conducta, donde los comportamientos que acarrean un beneficio tienen una mayor probabilidad de repetirse.

Sin embargo, en otros aspectos existen diferencias entre el aprendizaje humano y el de las máquinas (Lake, 2015):

1. El aprendizaje humano es dinámico y cambiante en función del contexto y de circunstancias vitales. Hay hechos que ocurren durante la infancia, en la madurez o en la vejez, y se pueden dar en el contexto de enfermedades, crisis vitales o situaciones vivenciales especiales que van a condicionar nuestro aprendizaje.

2. Es variable entre persona y persona: hay sujetos con exposición vital a muchos acontecimientos mientras que otros tienen una vida con menos experiencias vitales. Existen también diferencias cualitativas, ya que personas diferentes, ante un mismo acontecimiento vital, pueden extraer diferentes vivencias.

3. Podemos exponer a las máquinas a situaciones simuladas o reales que éticamente sería imposible con humanos.

4. La velocidad de adquisición de datos por parte de una máquina es más rápida. La máquina no tiene otras funciones (alimentación, descanso u ocio) ni se agota (trabaja 24 horas al día).

La toma de decisiones puede representarse mediante algoritmos lógicos que pueden traducirse a un lenguaje interpretable por las máquinas. La relación existente entre el Big Data y la Inteligencia Artificial es que estas cantidades ingentes de datos en múltiples formatos (Big Data) sirven para entrenar y dotar de experiencia a una máquina para que desarrolle y entrene algoritmos de toma de decisiones autónomas (Obermeyer, 2016).

Imaginemos que una máquina "sabe" todo el contenido que se ha publicado en salud en los últimos 10 años, que está dotada de herramientas lógicas que le permitan establecer relaciones entre ellos y que es capaz de pasar de un caso concreto a uno global. Dispondríamos entonces de una herramienta de toma de decisiones diagnósticas más fiable que el mejor médico del mundo, ya que ninguno va a ser capaz de manejar todas las variables con tanta rapidez y precisión como lo hacen los sistemas informáticos.

Podemos distinguir dos tipos de aprendizaje (Isasi, 2004) aplicados a las máquinas:

1. Aprendizaje supervisado. Con participación humana, que determina las relaciones "correctas" e "incorrectas" de la máquina. La función humana es "reforzar" los aciertos para que tiendan a repetirse.

2. Aprendizaje automático o Machine Learning. Consiste en alimentar de experiencia a la máquina (a partir de Big Data) y que sea, mediante unas normas lógicas iniciales, capaz de ir aprendiendo de manera independiente a partir de la experiencia que proporcionan los datos sin el concurso humano continuado. 
Nuevas herramientas de comunicación digitales entre profesionales de la salud y pacientes. A propósito del proyecto Dejal@Bot

Existen numerosos ejemplos de Machine Learning basados en estructuras lógicas dispuestas en capas complejas (algo parecido a la interconexión de redes neuronales). Muchas de estas capas están "especializadas" en temas concretos, como las neuronas, con capas especializadas en "ver", "escuchar" o "relacionar" (Julián, 2016).

Estos procesos no son explicados de manera exclusivamente matemática, ya que se establecen patrones iniciales de aprendizaje (esqueleto neuronal básico) que se van modificando y mejorando a través de experiencias proporcionadas por Big Data y generando sus propias "conexiones neuronales". En poco tiempo, y disponiendo de la cantidad de datos suficiente, podemos tener un sistema especializado capaz de tomar decisiones.

El uso de sistemas robóticos en salud plantea un problema en la comunicación hombre-máquina. El robot se debe expresar de forma que los usuarios puedan comprenderlo y debe interpretar lo que esos usuarios expresen sin que tengan que hacerlo de modo distinto a como lo harían para comunicarse con otra persona. En definitiva, se persigue imitar a los seres humanos en su manera de interactuar (Alonso Martín, 2014).

El desarrollo de robots antropomórficos para la atención directa a personas puede producir rechazo en el ser humano al relacionarse con una máquina con aspecto humanoide. Es la denominada teoría del valle inquietante, que recibe este nombre a partir de la definición de "lo inquietante" procedente del ensayo "En la psicología de lo inquietante" de Ernst Jentsch (1906). "Lo inquietante" es una sensación perturbadora ante algo que es y no es familiar al mismo tiempo. Una situación u objeto que se parece mucho a algo cotidiano y bien conocido, pero que nos causa malestar. Esta teoría es retomada por Masahiro Mori en 1970 para describir la relación humano/robot, que es cada vez más positiva siempre y cuando el robot mantenga apariencia de robot y seamos conscientes que se trata de una máquina a nuestro servicio. Cuando el robot va adquiriendo rasgos antropomórficos, la respuesta emocional de un humano será cada vez más negativa hasta llegar al rechazo por la "inquietud" generada.

Esta teoría se puede explicar de la siguiente forma (Alonso, 2014); si una entidad es bastante diferente al humano, sus características se verán más resaltadas, y generará simpatía; mientras que si la entidad tiene apariencia humana, se harán evidentes sus "diferencias", pudiendo crear sentimientos de rechazo (figura 1).

1. Un robot con aspecto humano puede actuar en nuestro subconsciente generando la idea que todo ser humano es un elemento mecánico carente de alma.

2. Si la mayoría de los androides son copias de personas reales se convierten en dobles, provocando miedo a ser reemplazado.

3. La torpeza de movimientos del androide podría generar rechazo al provocar miedo de pérdida de control corporal.

4. La existencia de androides puede ser percibido como amenaza al concepto de identidad humana. 
Nuevas herramientas de comunicación digitales entre profesionales de la salud y pacientes. A propósito del proyecto Dejal@Bot

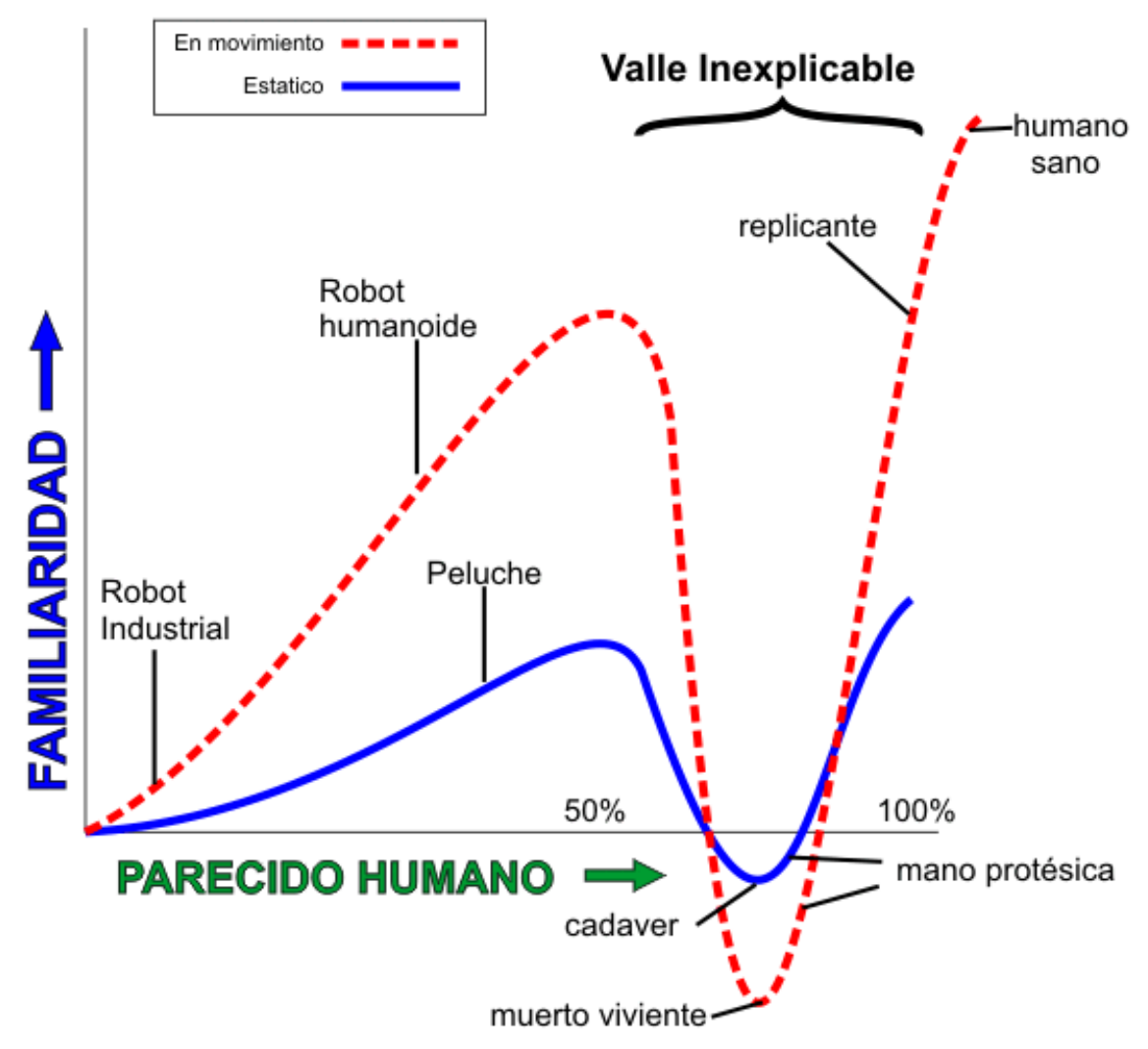

Figura 1. Representación del "valle inquietante" descrito por Masahiro Mori.

Fuente: Imagen original de Edgar Talamanes.

https://es.wikipedia.org/wiki/Valle inquietante\#/media/Archivo:Valle inexplicable2.gif

Sin embargo no siempre se genera rechazo. Investigadores como Hiroshi Ishiguro, director del Laboratorio de Inteligencia Robótica de la Universidad de Osaka, ha creado su clon robótico dotado de inteligencia artificial que actúa como doble de su creador en el proyecto Geminoid.

Este proyecto (Ishiguro, 2019) sobrepasa el efectismo de la creación de clones desarrollando líneas de investigación en la relación humano-robot en búsqueda del concepto de lo que es "ser humano" y estudiando las interacciones tanto desde el punto de vista de influencia personal y social en los humanos como las modificaciones que se generan en la inteligencia artificial.

\section{PROYECTO DEJAL@BOT}

El proyecto Dejal@Bot nace hace en 2014, cuando un grupo de médicos relacionados con la Sociedad Madrileña de Medicina de Familia (SoMaMFyC) pertenecientes al Grupo de Abordaje al Tabaquismo (GAT) y al Grupo de Nuevas 
Nuevas herramientas de comunicación digitales entre profesionales de la salud y pacientes. A propósito del proyecto Dejal@Bot

Tecnologías, nos planteamos evaluar el impacto de herramientas tecnológicas en la deshabituación tabáquica de nuestros pacientes.

En un repaso a los ensayos clínicos publicados vimos que había artículos referidos al apoyo con mensajes SMS y con algunas aplicaciones para móviles (apps). Tras evaluar las principales apps, ninguna de ellas se adaptaba a las directrices marcadas por la evidencia científica a través de las guías de práctica clínica, por lo que nos propusimos construir una propia. El coste era considerable y recurrimos a fondos públicos mediante la solicitud de una beca FIS (Fondos de Investigación en Salud) en el año 2015. Esta beca fue denegada y el proyecto quedó en suspenso unos meses.

Estábamos satisfechos de la metodología elegida y creíamos en la pertinencia del proyecto ya que existían muy pocos ensayos clínicos en salud digital y se estaban comercializando productos sin demostración previa de sus beneficios.

Estuvimos un año trabajando y durante ese periodo de tiempo se empezó a hablar de la aplicación de inteligencia artificial en salud. Aparecieron los primeros chatbots en salud y se nos ocurrió la idea de utilizar un chatbot en lugar de una app. Reformulamos la solicitud y nos presentamos en la convocatoria FIS del 2017 donde nos concedieron la beca.

El tabaquismo constituye la principal causa de enfermedad y muerte evitable en el mundo, provocando de forma directa 5 millones de muertes anuales (WHO, 2012). En España fuma a diario un $24 \%$ de la población, y un 3,1\% más es fumador ocasional (INE, 2013) lo que provocó cerca de 52000 muertes directas en el año 2014. (Ministerio de Sanidad, 2016)

A la mayoría de los fumadores les gustaría dejar de fumar, y el porcentaje de fumadores que lo intentan es alto (hasta 78 intentos por cada 100 fumadores durante un año en Reino Unido), pero sólo del 2 al 3\% se mantienen sin fumar un año después. (Averyard y West, 2007)

Los profesionales sanitarios somos muy efectivos y eficientes cuando intervenimos sobre el paciente fumador, multiplicando por más de tres sus posibilidades de abstinencia. Sin embargo, solo 1 de cada 20 intentos se realiza con supervisión profesional. Los factores causantes de estas bajas tasas de intervención son el déficit formativo de los profesionales, su convencimiento de la baja utilidad de la intervención y la falta de tiempo percibida para desarrollarla. (Saito, 2010)

Por ello, pensamos que la existencia de una herramienta fácil de utilizar, accesible a través de un teléfono móvil y que tuviera los conocimientos de un "experto" en tabaquismo podría tener un papel en el proceso de deshabituación tabáquica.

La tecnología de bots en dispositivos móviles tiene varias ventajas frente a las aplicaciones (Apps) habituales:

Revista de Comunicación y Salud, 2019, Vol. 9, n² 2, pp. 55-70 
Nuevas herramientas de comunicación digitales entre profesionales de la salud y pacientes. A propósito del proyecto Dejal@Bot

1. Un chatbot no es un programa que haya que instalar y no ocupa espacio en la memoria del teléfono.

2. Respeta la privacidad del paciente/usuario sin acceso a datos personales.

3. No precisa entrenamiento ya que la comunicación se produce mediante una app de mensajería (aplicación más extendida entre los usuarios de móviles).

4. Usa un interfaz estandarizado favoreciendo usabilidad y adherencia.

Nuestro bot ha sido diseñado integrando componentes conductuales, motivacionales, de resolución de problemas y prevención de recaídas, estructurados en intervenciones de utilidad demostrada para ayudar a dejar de fumar y recomendadas en las guías de práctica clínica basadas en la evidencia (NICE, 2008).

Invitamos a los lectores de este artículo a conocer este proyecto independiente a través de nuestra página web (www.dejalobot.es) donde generamos contenidos relacionados con el proyecto en abierto para favorecer otros proyectos similares que se puedan estar realizando.

Se trata de un ensayo clínico aleatorizado diseñado para demostrar la efectividad de un bot conversacional para un aspecto preventivo fundamental en el tratamiento de los ciudadanos como es el abandono del hábito tabáquico. Este estudio ha sido financiado por el Fondo de Investigaciones Sanitarias Instituto de Salud Carlos III con el número: PI17/01942 y el Fondo Europeo de Desarrollo Regional (FEDER).

Los financiadores no han desempeñado ningún papel en el diseño del estudio, la obtención de datos durante el trabajo de campo ni la interpretación de los mismos.

Para el trabajo de campo, se ha contado con 252 investigadores colaboradores, profesionales sanitarios de Atención Primaria, de 36 Centros de Salud de la Comunidad de Madrid.

El trabajo de campo se inició en octubre de 2018 y se extiende hasta finales del mes de noviembre de 2019, con 540 fumadores, que fueron aleatorizados a la rama control (deshabituación tabáquica presencial en consulta siguiendo los protocolos existentes para esta intervención) o a la rama intervención, y en los que, tras una primera visita para la inclusión y valoración inicial se descargaban en su teléfono móvil una aplicación de mensajería comercial habitual a través de la cual interactuaban con el chatbot que guiaría su proceso de deshabituación. El esquema de intervención se puede ver en la figura 2. 
Nuevas herramientas de comunicación digitales entre profesionales de la salud y pacientes. A propósito del proyecto Dejal@Bot

\begin{tabular}{c|c:c}
\hline Cronograma & Grupo Intervención & Grupo Control \\
\hline Visita inicial & 1 & 1 \\
\hline Aleatorización & $\mathrm{a}$ & $\mathrm{a}$ \\
\hline Intervención & $\mathrm{b}$ & $\mathrm{c}$ \\
\hline $\begin{array}{c}\text { Visita Final } \\
\text { (Resultados 6 meses) }\end{array}$ & $\mathrm{d}$ & $\mathrm{d}$ \\
\hline
\end{tabular}

\begin{tabular}{|c|l|}
\hline 1 & Visita presencial. Presentación del proyecto. Consentimiento informado \\
\hline a & Medición variables iniciales \\
\hline b & Instalación del chatbot y claves de acceso \\
\hline 2 & Uso del chatbot \\
\hline c & Tratamiento protocolizado habitual \\
\hline d & Medición de la abstinencia al tabaco \\
\hline
\end{tabular}

Figura 2. Pat Plot del ensayo clínico Dejal@bot.

La variable principal es la abstinencia a los 6 meses, referida por el fumador y comprobada bioquímicamente a través de cooximetría. Se han medido variables secundarias demográficas de los participantes e investigadores, variables de calidad de vida y variables relacionadas con la eficiencia del proceso.

Este estudio fue aprobado por los Comités de Ética de Investigación Clínica de la Comunidad de Madrid (13 de diciembre de 2017) y del Hospital Universitario 12 de Octubre de Madrid (Madrid, 30 de enero de 2018) cumpliendo con la legislación española sobre experimentación humana y respetando todos los principios bioéticos de autonomía, justicia, beneficencia y ausencia maleficencia, de acuerdo con los estándares de buena práctica de la Declaración de Helsinki y el Convenio de Oviedo.

Actualmente, estamos finalizando el trabajo de campo y no disponemos de resultados definitivos. Agradecemos el apoyo metodológico de la Fundación para la Investigación e Innovación en Atención Primaria (FIIBAP) desde la concepción inicial del estudio.

El protocolo del ensayo clínico ha sido aceptado para su publicación por la revista BMC Medical Informatics.

El diseño metodológico de trabajo ha sido un reto, pero mayor reto fue diseñar un chatbot con rasgos comunicativos "humanos" que en la rama intervención de nuestro 
Nuevas herramientas de comunicación digitales entre profesionales de la salud y pacientes. A propósito del proyecto Dejal@Bot

ensayo ofreciera consejo, apoyo, información y recordatorios, estableciendo una comunicación con un humano que cualquiera de los dos pudiera iniciar a través de un lenguaje natural.

\section{COMUNICÁNDONOS CON NUESTRO BOT}

La comunicación con el bot se realiza de diferentes maneras:

1. Comunicación a través de texto escrito. Un chatbot funciona a través de diccionarios de conceptos o ideas que se entrenan a través de palabras o frases habituales que describen un mismo concepto o idea. Estos diccionarios se agrupan por campos semánticos que establecen una serie de categorías. En nuestro caso, establecimos una serie de categorías relacionadas con las diferentes etapas, sentimientos o procesos relacionados con el abandono del hábito tabáquico. Así creamos una categoría que denominamos "motivos para dejar de fumar" con los siguientes campos semánticos: "salud/miedo/ enfermedad", "dinero", "rol ejemplar", "estética", "autoestima/libertad". Dentro de cada uno de los campos agrupamos una serie de ideas, palabras o conceptos con los que se suele expresar una situación determinada fabricando así un diccionario inicial. Así, en el caso del campo "estética" incluimos conceptos como "dientes amarillos", "mal aliento", "arrugas", "me hago viejo", "me hago vieja", "envejezco", y así hasta 20 conceptos iniciales.

Cuando el bot acude a una categoría/campo semántico/diccionario y "no encuentra" la palabra o concepto pero cree que ha de encontrarse allí salta un aviso al programador preguntando si esa frase escrita por el humano corresponde a una categoría determinada. En caso que el programador conteste afirmativamente el bot incluye esa nueva palabra o frase en el diccionario correspondiente. Es decir, con el uso continuado va aprendiendo y completando cada uno de los diccionarios. En caso de no ser así es el programador quien recoloca el concepto en cuestión en el diccionario correspondiente de manera que el bot "aprende" nuevos sinónimos y va delimitando cada uno de los diccionarios.

Nuestro bot tiene 20 categorías, 235 campos semánticos y se inició con más de 10.000 conceptos en sus diccionarios.

Como curiosidad, hemos creado una categoría "tacos" para generar alguna respuesta al interlocutor que los utiliza como por ejemplo "no me hables así, soy un robot pequeño y no me gustan las palabrotas" o "no te enfades, no es para tanto".

2. Comunicación a través de emoticonos: Al utilizar una comunicación a través de un chat y debido al gran uso de emoticonos en este canal de comunicación decidimos que el bot los utilizara dentro de un lenguaje de texto. Así creamos una serie de categorías que definían los estados de ánimo expresados por cada uno de los emoticonos, de forma que los pudiera utilizar dentro de sus diccionarios para expresar una emoción o situación concreta.

3. Comunicación multimedia: A través de un sistema de chat podemos compartir archivos en diferentes medios que se pueden ejecutar o reproducir sin necesidad 
Nuevas herramientas de comunicación digitales entre profesionales de la salud y pacientes. A propósito del proyecto Dejal@Bot

de salir del programa. De esta forma hemos elaborado 17 vídeos y 20 infografías que ofrecen información que difícilmente podríamos expresar con texto.

La comunicación con un bot es bidireccional y por lo tanto puede ser iniciada por el humano (bot reactivo) o por la propia máquina (bot activo).

La primera interacción es activa, generada por el bot:

"PRESENTACIÓN DEL BOT Y DEL PROTOCOLO

B: ¡Hola, ser humano! ¿Cómo estás? ¡Bienvenid@!

B: Me llamo Dej@lo Bot y voy a ser tu asistente para ayudarte a dejar de fumar.

$B$ : He sido programado por expertos en tabaquismo siguiendo las directrices científicas más actuales para poder ayudarte y acompañarte durante todo este proceso.

B: En todo momento estaré contigo. Sólo tienes que llamarme si me necesitas.

B: Mi forma de actuar es sencilla. Sigo un programa formal para ayudar a los humanos a dejar de fumar similar al que utilizan en las mejores clínicas especializadas. Lo iré desarrollando contigo dos semanas antes de dejar de fumar y varios meses después.

B: Hoy te haré algunas preguntas, y los siguientes días te daré tareas y consejos. Las tareas no son obligatorias, pero los humanos que las hacen aumentan mucho sus posibilidades de dejar de fumar, pues te ayudan a anticipar y resolver los problemas más habituales que se plantean.

B: Para motivarte a trabajar, te iré dando una serie de insignias que dan acceso a niveles superiores del proceso si vas cumplimentando las tareas principales"

El bot tiene las siguientes acciones de comunicación activas:

1. En la presentación o activación del bot.

2. En cada una de las fases determinadas por el equipo investigador. Según la evidencia científica hay que realizar una serie de tareas previas a la fecha del abandono del hábito tabáquico en las que se explora la situación del fumador y se ofrecen conocimientos (actitudes ante deseos de fumar, actitudes ante potenciales recaídas, cómo manejar el deseo de tabaco, elaborar una lista de motivos para el abandono, exploración de mitos existentes relacionados con el tabaco...). Estas actividades se han de realizar en días concretos y antes del "día D" o fecha determinada por el fumador como el primer día sin tabaco. Dependiendo de los conceptos que queremos que el fumador aprenda, el bot se comporta de manera activa en unos días determinados por los investigadores y a una hora elegida por el fumador.

3. Después del "día D", el bot tiene un contacto diario durante los tres primeros días, luego cada dos días, posteriormente semanal y finalmente mensual.

Las comunicaciones reactivas se producen cuando el fumador inicia comunicación a través del chat y se ofrecen respuestas a las preguntas que el humano hace. 
Nuevas herramientas de comunicación digitales entre profesionales de la salud y pacientes. A propósito del proyecto Dejal@Bot

“MENÚ REACTIVO (cuando el paciente entra de motu propio en cualquier momento) F: "-"

B: ¡iHola humano/a!! ¿En qué te puedo ayudar?

B: Si tu duda se identifica con alguna de las posibilidades que te ofrezco aquí debajo, señala la opción correspondiente. Si no es así, cuéntamela de forma clara y sencilla

F: (desarrollar campos semánticos)"

\section{COMPENSACIONES Y RECOMPENSAS}

En las intervenciones para el cambio de conductas, cobran gran importancia el establecimiento de "premios" o situaciones agradables que potencien cualquier cambio positivo que haga el paciente. Con ello, utilizamos a nuestro favor al condicionamiento operante, intentando que la conducta identificada como positiva tenga también efectos beneficiosos a corto plazo.

Se conoce como gamificación o ludificación a la utilización de técnicas, elemento y dinámicas propias de los juegos en actividades no recreativas con la finalidad de potenciar la motivación, reforzar conductas, mejorar la productividad o facilitar el aprendizaje (Deterding, 2001).

Con estos condicionantes, hemos establecido unos sistemas de compensaciones y premios generando una capa de gamificación dentro del bot. Estas actividades también son formas de comunicación entre el humano (paciente en proceso de abandono del tabaco) y la máquina.

1. Insignias: Las insignias se van adjudicando según se van realizando una serie de actividades o hitos a lo largo del proceso, sobre todo en la primera parte, desde que se establece la primera conexión con el bot hasta el "día D" (o primer día sin humo). Hemos elegido un sistema de 5 estrellas (similar a los sistemas de puntuación en numerosos servicios web) a los que el usuario está acostumbrado. Estas estrellas se van otorgando cuando el fumador realiza una serie de tareas esenciales para el proceso como son: elaboración de la lista personal de motivos para el abandono del tabaco, determinación del día $\mathrm{D}$ o selección de una persona de confianza a quien llamar en caso de crisis.

Las insignias son una serie de recompensas que van marcando la evolución del proceso y distinguen a un usuario respecto al resto de la comunidad por los logros obtenidos.

2. Otras recompensas: En el primer día de contacto con el bot se le pregunta al usuario cuál es su grupo de música favorito y se comprueba (figura 3). Este dato no se vuelve a utilizar hasta después de varias semanas pero queda almacenado en la memoria del chatbot. A partir del "día D", en cada nueva conexión, la primera pregunta que no realiza el bot es "¿has fumado desde la última vez que hablamos?", si la respuesta es "no" el bot nos regala de forma aleatoria un vídeo de YouTube de nuestro artista favorito. Si la respuesta es "si" explora los motivos por los cuales hemos recaído y nos ofrece la posibilidad de marcar un nuevo "día D" cuando estemos de nuevo preparados para ello.

Revista de Comunicación y Salud, 2019, Vol. 9, nº 2, pp. 55-70 
Nuevas herramientas de comunicación digitales entre profesionales de la salud y pacientes. A propósito del proyecto Dejal@Bot

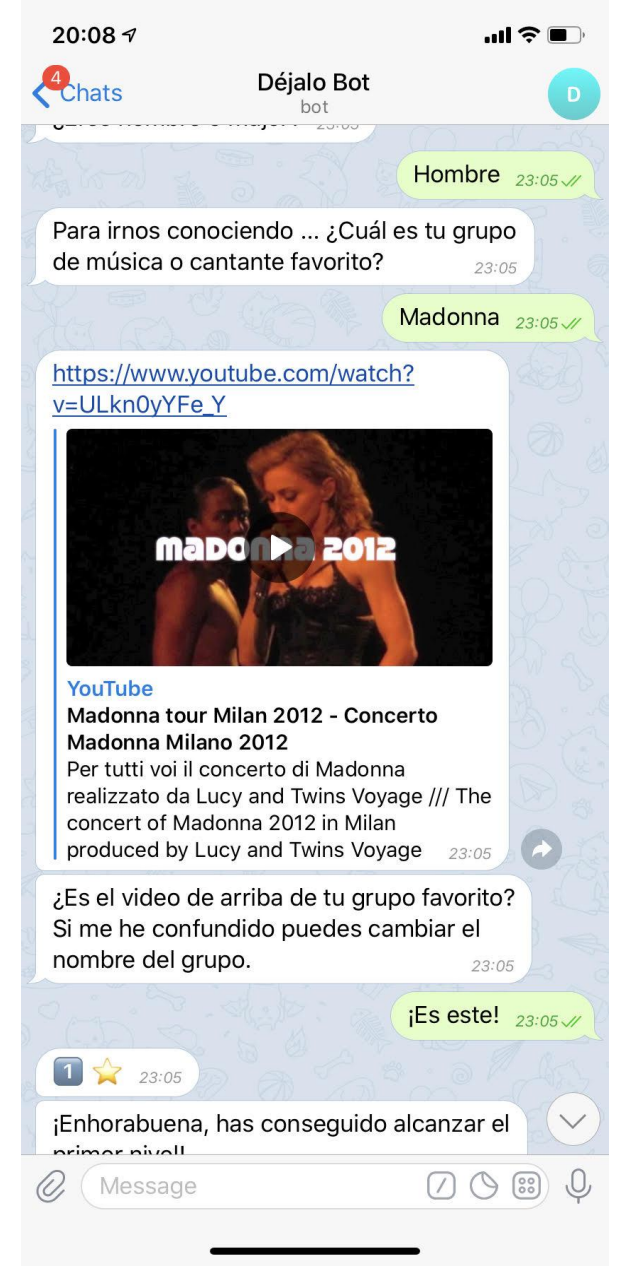

Figura 3. Pantallazo de diálogo real del chatbot en el primer día cuando explora y comprueba nuestro grupo musical favorito.

\section{HUMANIZANDO NUESTRO BOT PARA MEJORAR LA COMUNICACIÓN}

Utilizar un chatbot que se comunica con el ser humano a través de una aplicación conversacional y que permite mantener un diálogo utilizando elementos multimedia (texto, imágenes, vídeos) evita el denominado valle inquietante ya que, aunque el humano es consciente que está hablando con una máquina, esta no tiene una apariencia humana.

El proceso de dejar de fumar es una decisión personal que afecta a nuestro plano íntimo y, tener como interlocutor una máquina podría significar una comunicación fría y poco agradable o impersonal para el usuario de esta herramienta.

Humanizar la tecnología es un reto en un entorno donde cada vez disponemos de más herramientas para realizar estas acciones ya que la tecnología ha de estar al servicio del ser humano y no al servicio de sus productos (García Avilés, 2008). 
Así, hemos buscado darle al bot una imagen sin desligarlo de su carácter de máquina; queríamos humanizar nuestro robot acorpóreo.

Dentro de la cultura cinematográfica de los siglos XX y XXI tenemos ejemplos de humanización de robots. Aspectos agresivos como en las películas Terminator (Cameron, 1984) o Robocop (Verhoeven, 1987); con sentimientos prácticamente indistinguibles de los humanos como en la película Blade Runner (Scott, 1982); aspectos infantiles como Wall-e (Stanton, 2008); o robots que se relacionan entre ellos como C3PO y R2D2 en los diferentes episodios cinematográficos de la serie de la Guerra de las Galaxias (Stars Wars 1977-2019).

Deseábamos una imagen de un robot cercano a las pasiones humanas sin dejar de tener un aspecto físico de robot y descubrimos en nuestra búsqueda a Bender B. Rodríguez, robot de la serie Futurama (FOX 1999-2013).

En Futurama, los robots representan seres sin limitaciones éticas, lo que les permite ocupar un lugar ruin y miserable en la sociedad, aunque forman parte plena de ella. Utilizando un elemento «poco familiar» como los robots, se nos puede mostrar «algo familiar» como los defectos del ser humano, canalizados a través de Bender.

Buscamos imágenes sin derechos de autor para poder utilizarlas en nuestro proyecto y a través de diferentes modelos vectoriales generamos a nuestro Dejal@Bot. (Figura 4):

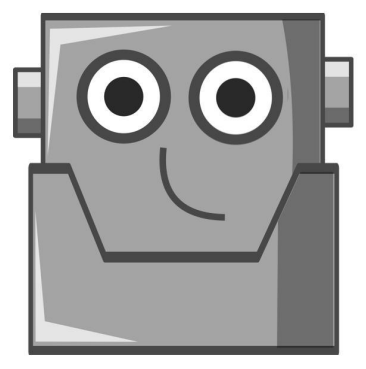

Figura 4. Aspecto original de Dejal@Bot.

Fuente: Elaboración propia a partir de imágenes vectoriales libres de derechos.

Le teníamos que dotar de sentimientos humanos, ya que queríamos que fuera un robot que acompañara al humano en su proceso de dejar de fumar y que pasara por las mismas situaciones anímicas que este. La mejor forma que disponemos en la actualidad para demostrar sentimientos de forma gráfica en entornos de chat son los denominados emoticonos, que se han establecido como estándares en su significado como elementos de comunicación.

El siguiente paso fue crear imágenes faciales que representaran dichos estados de ánimo. (Figura 5): 

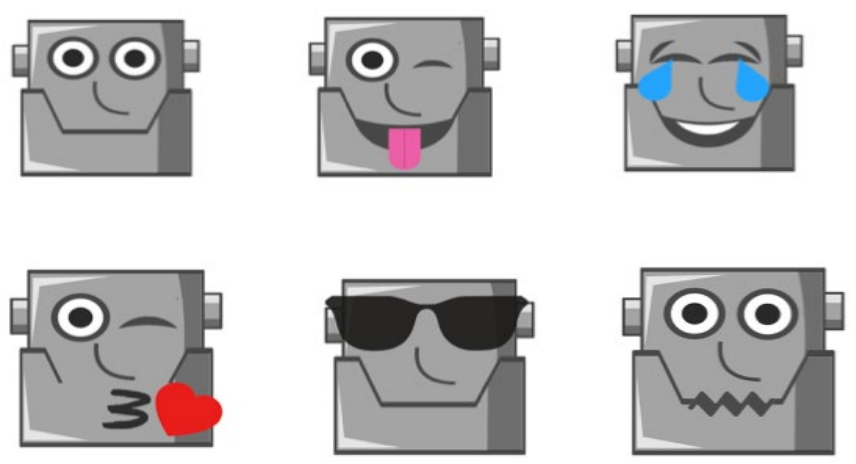

Figura 5. Diferentes imágenes de Dejal@Bot para representar estados de ánimo. Fuente: Elaboración propia a partir de imágenes vectoriales libres de derechos.

Sin embargo, el gran reto tecnológico ha sido el establecer un conjunto de campos semánticos de conceptos para poder establecer la comunicación entre el humano y la máquina a través de un lenguaje natural capaz y que incluyera la gran variabilidad de expresiones existentes para describir diferentes estados de ánimo en el proceso del abandono del hábito tabáquico. El trabajo para ellos ha sido ingente y de difícil descripción.

Actualmente, el Bot se encuentra en un proceso de mejora continua donde tienen gran peso las opiniones de sus usuarios.

\section{REFERENCIAS}

Alonso Martín, F. (2014). Sistema de Interacción Humano-Robot basado en Diálogos Multimodales y Adaptables. (Tesis doctoral). Departamento de ingeniería de sistemas y automática. Universidad Carlos III, Leganés. Madrid. Disponible en http://roboticslab.uc3m.es/roboticslab/sites/default/files/tesis 0.pdf

Alonso, J. R. (2014). Lo inquietante [Internet]. Neurociencia. Disponible en https://jralonso.es/2014/11/20/lo-inquietante/

Aveyard, P. \& West, R. (2007). Managing smoking cessation. BMJ 2007, 335:37-41 doi:10.1136/bmj.39252.591806.47. Disponible en https://www.ncbi.nlm.nih.gov/pmc/articles/PMC1910650/

Cameron, J. (1984). Terminator. [Cinta cinematográfica]. Estados Unidos: Pacific Western / Hemdale Film Corporation. Distribuida por Orion Pictures. 
Nuevas herramientas de comunicación digitales entre profesionales de la salud y pacientes. A propósito del proyecto Dejal@Bot

Deterding, S., et al. (2011). Gamification: Toward a Definition. Disponible en http://gamification-research.org/wp-content/uploads/2011/04/02-Deterding-KhaledNacke-Dixon.pdf

García Avilés, J. A. (2009). La comunicación ante la convergencia digital: algunas fortalezas y debilidades. Signo y Pensamiento, 54, 102-113. Disponible en https://revistas.javeriana.edu.co/index.php/signoypensamiento/article/view/4529

Instituto Nacional de Estadística (INE), (2013). Encuesta Nacional de Salud 2011-2012. Disponible en http://www.ine.es/daco/inebase mensual/marzo 2013/encuesta nacional salud.zip

Viñuela, I., Pedro y Galván L., e Inés M. (2004). Redes de neuronas artificiales. Un Enfoque Práctico. Madrid, España: Editorial Pearson Educación.

Ishiguro, H. (2019). Studies on Interactive Robots. In Living Machines, Kasugano International Forum. Nara. Disponible en http://livingmachinesconference.eu/2019/plenarytalks/

Jentsch, E. (1906). "Zur Psychologie des Unheimlichen" On the Psychology of the Uncanny. Disponible en http://www.art3idea.psu.edu/locus/Jentsch uncanny.pdf

Julián, G. (2016). Las redes neuronales: qué son y por qué están volviendo. Revista Xataka. Disponible en https://www.xataka.com/robotica-e-ia/las-redes-neuronalesque-son-y-por-que-estan-volviendo

Lake, B.; Salakhutdinov, R. \& Tenenbaum, J. B. (2015). Human-level concept learning through probabilistic program induction. Science, 350, 1332-1338. Disponible en https://doi.org/10.1126/science.aab3050

Ministerio de Sanidad, Servicios Sociales e Igualdad (2016). Muertes atribuibles al consumo de tabaco en España, 2000-2014. Madrid: Ministerio de Sanidad, Servicios Sociales e Igualdad. Disponible en https://www.msssi.gob.es/estadEstudios/estadisticas/estadisticas/estMinisterio/mortal idad/docs/MuertesTabacoEspana2014.pdf

Mori, M. (1970). The uncanny valley. Energy, 7(4), 33-35. Disponible en http://www.movingimages.info/digitalmedia/wp-content/uploads/2010/06/MorUnc.pdf

National Institute for Health and Clinical Excellence (NICE), (2008). Smoking cessation services in primary care, pharmacies, local authorities and workplaces, particularly for manual working groups, pregnant women and hard to reach communities. NICE public health guidance, 10. Disponible en https://www.nice.org.uk/guidance/ph10/resources/smoking-cessation-services-inprimary-care-pharmacies-local-authorities-and-workplaces-particularly-for-manual- 
Nuevas herramientas de comunicación digitales entre profesionales de la salud y pacientes. A propósito del proyecto Dejal@Bot

working-groups-pregnant-women-and-hard-to-reach-communities-review-proposalconsultation2

Obermeyer, Z. \& Emanuel, E. J. (2016). Predicting the future-big data, machine learning, and clinical medicine. The New England journal of medicine, 375(13), 1216.

Saito A.; Nishina, M.; Murai, K. \& cols. (2010). Health proffessionals perceptions of and potential barriers to smoking cessation care. BMC Research Notes 2010; 3:329. doi: 10.1186/1756-0500-3-329. Disponible en https://www.ncbi.nlm.nih.gov/pmc/articles/PMC3016266/

Scott, R. (1982). Blade Runner. [Cinta cinematográfica]. Estados Unidos: Warner Bros / Ladd Company / Shaw Brothers.

Stantona, Andrew (2008). Wall-e. [Cinta cinematográfica]. Estados Unidos: Walt Disney Pictures / Pixar Animation Studios.

Verhoeven, Paul (1984). Robocop. [Cinta cinematográfica]. Estados Unidos: Orion Pictures Corporation.

World Health Organization (2012). WHO global report mortality attributable to tobacco [Internet]. Geneva, Switzerland: World Health Organization. Disponible en http://whqlibdoc.who.int/publications/2012/9789241564434 eng.pdf 